\title{
Sports-related spinal cord injury in Japan (From the nationwide spinal cord injury registry between 1990 and 1992)
}

\author{
Shinsuke Katoh ${ }^{1,2}$, Hikosuke Shingu ${ }^{1,3}$, Takaaki Ikata ${ }^{1,2}$ and Eiji Iwatsubo ${ }^{1,4}$ \\ ${ }^{1}$ Injury Prevention Committee of the Japan Medical Society of Paraplegia, ${ }^{2}$ Department of Orthopedic Surgery, \\ School of Medicine, the University of Tokushima, Tokushima 770, ${ }^{3}$ Chief of the Committee, Department of \\ Orthopaedic Surgery, San-in Rosai Hospital, 1-8-1 Kaikeshinden, Yonago 683, ${ }^{4}$ Spinal Injuries Center, 550-4 Igisu, \\ Iizuka, Fukuoka 820, Japan
}

The Injury Prevention Committee of the Japan Medical Society of Paraplegia (JMSoP) conducted a nationwide epidemiological survey on spinal cord injury (SCI) using postal questionnaires for 3 years periods from 1990 to 1992, and the annual incidence of the spinal cord injury was estimated as 40.2 per million. From this registry, we investigated SCI related to sports activities.

In 3 years, 528 patients were registered and 374 of them had neurological deficits. The incidence was 1.95 per million per annum. Mean age at injury was 28.5 years (10-77), and $88.1 \%$ of the patients were males. Diving was the commonest cause of SCI $(21.6 \%)$, which was followed by skiing $(13.4 \%)$, football including rugby, American football and soccer $(12.7 \%)$, sky sports $(7.0 \%)$, judo $(6.8 \%)$ and gymnastics $(6.6 \%)$. Mean age at injury was higher than 30 years in skiing (38.6 years) and sky sports (38.2 years). Cervical injury was predominant in all but sky sports and accounted for $83.5 \%$ of SCI. Motor complete paralysis was reported in $35.0 \%$ of the patients. Bony injury was observed in $55.9 \%$ of the patients; most of the patients who sustained the SCI in diving and sky sports had bony injury, and no bony injury was detected in more than a half of the patients who sustained injuries in skiing, judo or gymnastics.

Although the percentage of sports-related SCI was small in the present study as compared to the data from previous reports, it is not difficult to imagine the increase in the number of sports-related SCI. We have launched an injury prevention campaign and are planning to conduct a similar study in future to evaluate the effect of the campaign as well as the changes in the incidence and pattern of SCI.

Keywords: spinal cord; trauma; epidemiology; sports

\section{Introduction}

There have been epidemiological studies which collected spinal cord injury (SCI) patients who sustained their injury in individual sports activity, however, to our knowledge, a nationwide survey on all kinds of sports activities has not yet been available. The Injury Prevention Committee of the Japan Medical Society of Paraplegia (JMSoP) conducted a nationwide epidemiological survey on spinal cord injury (SCI) using postal questionnaires from January 1990 to December $1992 .{ }^{1}$ There was 7471 registered patients with neurological symptoms from Frankel A to $\mathrm{D}$ (Table 1). Since the mean response rate was $51.4 \%$, the annual incidence of spinal cord injuries was estimated as 40.2 per million. In the present report, we analysed sports-related spinal cord injuries.

\section{Materials and methods}

The Injury Prevention Committee of JMSoP and regional supervisors of JMSoP sent out study charts

Table 1 Incidence of spinal cord injury

\begin{tabular}{lcccc}
\hline & 1990 & 1991 & 1991 & Mean \\
\hline Population (millions) & 123.61 & 124.04 & 124.45 & 124.03 \\
Number of departments & 9570 & 8619 & 8577 & 8822 \\
Response rate & $56.6 \%$ & $48.3 \%$ & $49.0 \%$ & $51.4 \%$ \\
Registered number & 3465 & 3097 & 3190 & 3251 \\
Frankel grade A - D & & & & \\
$\quad$ Registered number & 2665 & 2372 & 2434 & 2490 \\
$\quad$ Estimated number & 4872 & 4986 & 5110 & 4989 \\
$\quad$ Incidence (per million) & 39.4 & 40.2 & 41.1 & 40.2 \\
$\quad$ Number of sports-related & 182 & 174 & 172 & 176.0 \\
$\quad$ injuries & & & & \\
Frankel grade A-D & & & & \\
$\quad$ Registered number & 128 & 121 & 125 & 124.7 \\
$\quad$ Estimated number & 234 & 256 & 255 & 248.3 \\
$\quad$ Incidence (per million) & 1.9 & 2.1 & 2.1 & 1.95 \\
\hline
\end{tabular}


in the form of a questionnaire by mail to all departments of orthopaedics, neurosurgery, rehabilitation and emergency medical service centres throughout the country, which were assumed to accept spinal injury patients, asking these institutions to return the filled-in questionnaire to the supervisor in each region. The institutions which had no spinal injury case were also asked to reply.

Concerning the severity of injury, patients with paralysis and paresis as well as those suffering only from numbness without motor paralysis were included, and the neurological deficits were classified according to Frankel's classification. ${ }^{2}$

The annual incidence was estimated from the number of registered patients and the questionnaire recovery rate. ${ }^{3}$ The estimated incidence was obtained from the number of patients registered and the questionnaire recovery rate at each prefecture, and compiled on regional basis (with the confidence limit of over $90 \%$ ).

Estimated SCI number $=\sum^{\text {Registered SCI number in each prefecture }} /$

Response rate in each prefecture

Only those who were injured between 1 January 1990 and 31 December 1992 were accepted for the study. Those who were treated on an outpatient basis were excluded. In the present study, only patients who suffered SCI from sports-related activities were included.

\section{Results}

During the study period, 528 patients were registered as sports-related SCI and 374 of them had neurological symptoms in Frankel A, B, C and D (Table 1). As the exposed population in Japan over the 3 years was 372.10 million, the incidence of sports-related SCI estimated from the number of registered patients and the recovery rate was 1.95 per million per annum. The age at the time of injury ranged from 10 to 77 years with the mean age of 28.5 years. The age distribution for diving, rugby and gymnastic accidents showed main peaks at the second decade, but accidents in sky sports and skiing occurred mainly in the older age groups (Figure 1). Out of the 528 registered patients, 465 $(88.1 \%)$ were males and $63(11.9 \%)$ females.

\section{Diving}

During the study period, 114 patients were registered, and all suffered cervical injuries (Figure 2, Table 2). There were two peaks in the second and the third decades, $80.7 \%$ of patients were below the age of 30 years (Figure 3). Among these patients, 51 had been injured while diving into swimming pools and 28 into a river or the sea. The site of accidents were not reported in 35 patients. Regarding the severity of neurological deficits, patients with Frankel A paralysis accounted

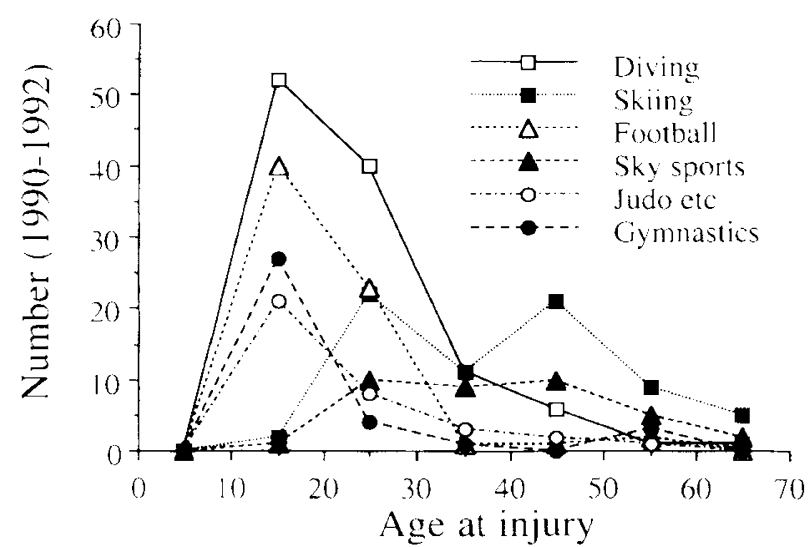

Figure 1 Age distribution and number of spinal cord injury from representative sports activities in Japan from January 1990 to December 1992

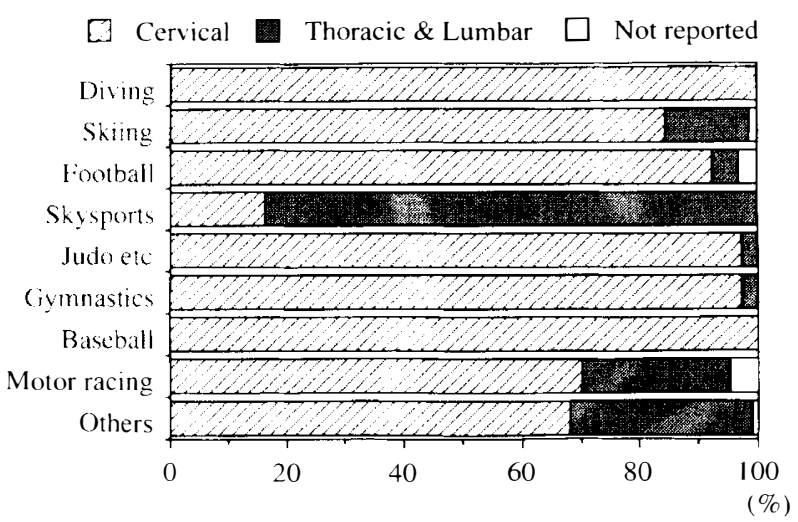

Figure 2 Ratio of the cervical spinal injury and the thoracic and lumbar spinal injury in individual sports activity

for $45.6 \%$ of diving accidents, which was the highest among all sports activities (Figure 4, Table 3). Bony injury was identified in $88 \%$ of patients (Figure 5, Table 4).

\section{Skiing}

Cervical injuries accounted for $85 \%$ of the 71 registered skiing accidents. Age at the time of injuries ranged widely from 15 years to 64 years (Figure 1). Frankel A patients accounted for $16 \%$ of the cases (Figure 4) and radiographic studies failed to demonstrate bony injury in about half of patients (Figure 5).

\section{Football (including rugby, American football and soccer)}

Fifty-two patients sustained their injuries while playing rugby, nine while playing soccer and six American football. The mean age at the time of accidents was 20.4 years and $93 \%$ of the patients were 25 years of age or younger (Figure 1). There were 62 cases of cervical injuries and $22 \%$ of all patients presented in 


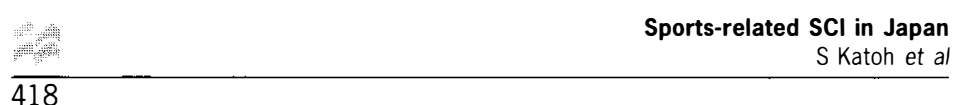

Table 2 Sports activities, levels of injuries, and age at the time of injury

\begin{tabular}{|c|c|c|c|c|c|c|c|c|}
\hline$\ldots$ & No. of patients & Male & Sex & Female & Cervical & $\begin{array}{l}\text { Level of injury } \\
\text { Thoracolumbar }\end{array}$ & Unknown & $\begin{array}{c}\text { Mean age } \\
\text { at injury (yo) }\end{array}$ \\
\hline Diving & $\begin{array}{c}114 \\
(21.5 \%)\end{array}$ & 100 & & 14 & 114 & 0 & 0 & $\begin{array}{c}21.9 \\
(10-69)\end{array}$ \\
\hline Skiing & $\begin{array}{c}71 \\
(13.4 \%)\end{array}$ & 59 & & 12 & 60 & 10 & 1 & $\begin{array}{c}38.6 \\
(15-30)\end{array}$ \\
\hline Football $^{1}$ & $\begin{array}{c}67 \\
(12.7 \%)\end{array}$ & 67 & & 0 & 62 & 3 & 2 & $\begin{array}{c}20.4 \\
(15-54)\end{array}$ \\
\hline Sky sports & $\begin{array}{c}37 \\
(7.0 \%)\end{array}$ & 34 & & 3 & 6 & 31 & 0 & $\begin{array}{c}38.2 \\
(19-63)\end{array}$ \\
\hline Judo etc ${ }^{2}$ & $\begin{array}{c}36 \\
(6.8 \%)\end{array}$ & 32 & & 4 & 35 & 1 & 0 & $\begin{array}{c}22.8 \\
(12-57)\end{array}$ \\
\hline Gymnastics & $\begin{array}{c}35 \\
(6.6 \%)\end{array}$ & 26 & & 9 & 34 & 1 & 0 & $\begin{array}{c}19.9 \\
(12-54)\end{array}$ \\
\hline Baseball & $\begin{array}{c}21 \\
(4.0 \%)\end{array}$ & 21 & & 0 & 21 & 0 & 0 & $\begin{array}{c}36.2 \\
(13-55)\end{array}$ \\
\hline Motor racing & $\begin{array}{c}20 \\
(3.8 \%)\end{array}$ & 19 & & 1 & 14 & 5 & 1 & $\begin{array}{c}27.8 \\
(20-57)\end{array}$ \\
\hline Swimming & $\begin{array}{c}13 \\
(2.5 \%)\end{array}$ & 10 & & 3 & 13 & 0 & 0 & $\begin{array}{c}34.7 \\
(15-50)\end{array}$ \\
\hline Basketball & $\begin{array}{c}9 \\
(1.7 \%)\end{array}$ & 6 & & 3 & 8 & 1 & 0 & $\begin{array}{c}17.4 \\
(14-23)\end{array}$ \\
\hline Horse riding & $\begin{array}{c}7 \\
(1.3 \%)\end{array}$ & 6 & & 1 & 6 & 1 & 0 & $\begin{array}{c}42.6 \\
(23-60)\end{array}$ \\
\hline Cycling & $\begin{array}{c}7 \\
(1.3 \%)\end{array}$ & 7 & & 0 & 6 & 1 & 0 & $\begin{array}{c}40.0 \\
(23-65)\end{array}$ \\
\hline Others & $\begin{array}{c}91 \\
(17.2 \%)\end{array}$ & 78 & & 13 & 62 & 28 & 1 & $\begin{array}{c}33.7 \\
(11-77)\end{array}$ \\
\hline Total & $\begin{array}{c}528 \\
(100 \%)\end{array}$ & 465 & & 63 & 441 & 82 & 5 & $\begin{array}{c}28.5 \\
(10-77)\end{array}$ \\
\hline
\end{tabular}

${ }^{1}$ : including rugby, American football and soccer. ${ }^{2}$ : including Judo, Sumo and wrestling

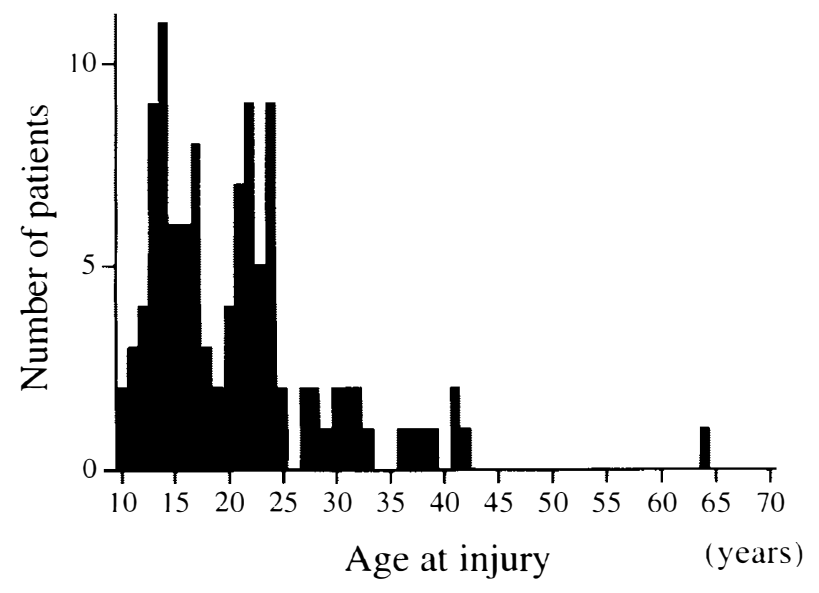

Figure 3 Age at the time of diving injury

Frankel A or B (Figure 4, Table 3). Bony injuries were not detected in $29(55.8 \%)$ of the patients injured in rugby, five $(83.3 \%)$ of those in American football and eight $(88.9 \%)$ of those in soccer.

\section{Sky sports}

Thirty-seven patients were registered and the mean age at the time of the accidents was 38.3 years (Table 2).
Thirty-three patients sustained their injury in paragliding. Thoracic or lumbar injuries accounted for more than $80 \%$ of all injuries (Figure 2). Fourteen $(37.8 \%$ ) of the 37 patients suffered neurological deficit graded Frankel A or B. Bony injury in the spinal column was found in $92 \%$ of the patients.

Judo etc. (including wrestling and sumo)

There were 36 registered patients in the study period, and the mean age at the time of the accidents was 22.8 years (Table 2). Twenty-six patients sustained SCI in judo, eight in wrestling and two in sumo, and all but four were males. Motor complete paralysis was reported in $14 \%$ of the patients. No bony injury was detected in 18 patients in judo $(69.2 \%)$, four patients $(50.0 \%)$ in wrestling and in any patient in sumo.

Gymnastics (including gymnastics at the school)

Thirty-five patients were registered and the mean age at the time of injuries was 19.9 years. Almost all of the patients suffered cervical injuries, one third of which were classified as Frankel A or B. Twenty-six patients participated in competitive gymnastics; 19 were males and seven were females. Nine patients had accidents while practising gymnastics at the school; seven were 
boys and two were girls. No bony injury was detected in 17 patients in competitive players $(65.4 \%)$ and in five patients $(55.6 \%)$ injured during school activities.

\section{Motor racing}

Twenty patients were registered and the mean age was 27.8 years. Thirteen patients sustained injuries in motocross. Fourteen of the 20 patients suffered cervical injuries and six suffered thoracic or lumbar injuries.

\section{Discussion}

Many previous reports described in spinal injuries caused by sports and recreational activities, and the incidence among all SCI ranged 7 to $15 \%{ }^{4-10}$ In the present study of the nationwide epidemiological survey on sports-related spinal injuries in all sports activities, the incidence of sports-related SCI was 1.95 per million per annum.

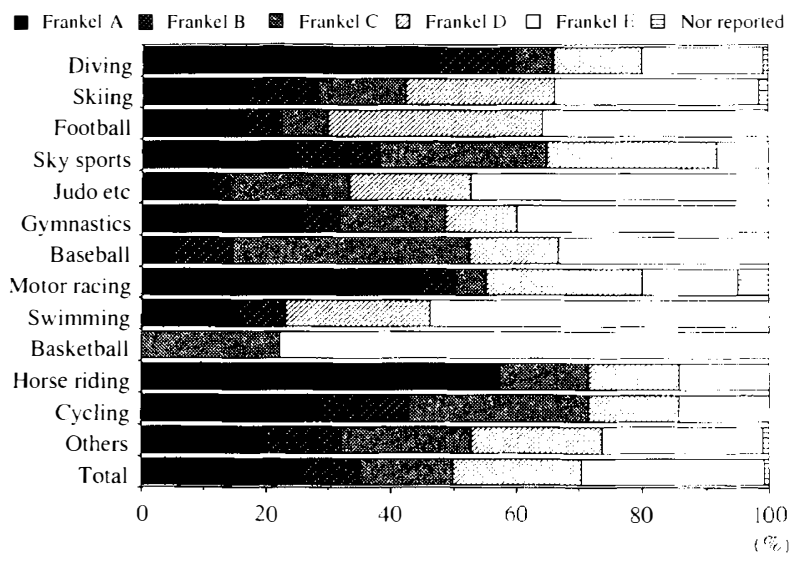

Figure 4 Ratio of each Frankel grade in individual sports activities
As was often reported, cervical injuries were predominant in all sport activities except sky sports. A narrow spinal canal had been reported to be a risk factor for cervical injuries. ${ }^{11-13}$ Although the high incidene of cervical injuries was one of the characteristics of SCI in Japan and the spinal canal of Japanese seems to be narrower than that of Caucasian, this predominancy of the cervical injuries in the sportsrelated SCI seemed not to be specific among the countries surveyed.

Diving accidents, which accounted for $2.6 \%$ of all injuries in the present study have been reported to be the commonest cause of sports-related SCI in the literature with a varying incidence from 4.9 to $9.0 \%{ }^{14-16}$ The age distribution in the present study seemed to be consistent with other reports, ${ }^{6}$ except for a sudden decrease in the number of patients at around the age of 18 which may be related to the educational system in Japan. The common sites of the accidents were swimming pools, especially in junior high school, which have a depth of 1.0-1.2 metres. Many accidents occurred in the absence of supervisors. ${ }^{17}$ The prevalence of severe injuries was also consistent with other reports. Bony injuries were not detected in about $10 \%$ of the patients, which was consistent with a previous report. ${ }^{18}$

There has been a tremendous increase in the number of recreational and competitive skiers in Japan and alpine skiing is predominant. To our knowledge, no data had been available on the incidence of SCI in skiing in Japan. Skiing was involved in $13.4 \%$ of all sports-related SCI or $0.95 \%$ of all SCI. Spinal injury rates were reported around $3 \%$ of the total. ${ }^{19}$ The majority of skiing accidents were reported by hospitals in the northern part of Japan where most of the skiing sites are located. It was interesting to note in the present study that bony injuries were not detected in more than half of the patients, and that skilful skiers were more prone to suffer SCI as compared to beginners.

Table 3 Sports activities and the severity of the neurological deficit

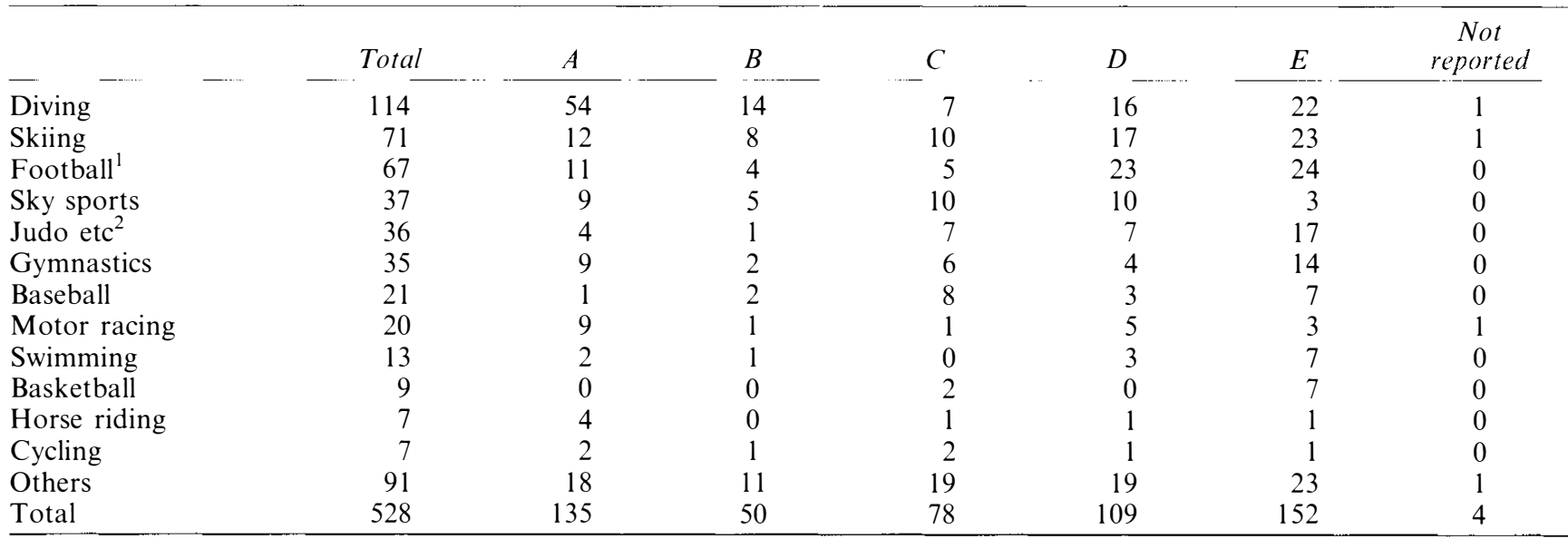

${ }^{1}$ : including rugby, American football and soccor, ${ }^{2}$ : including Judo, Sumo and wrestling 


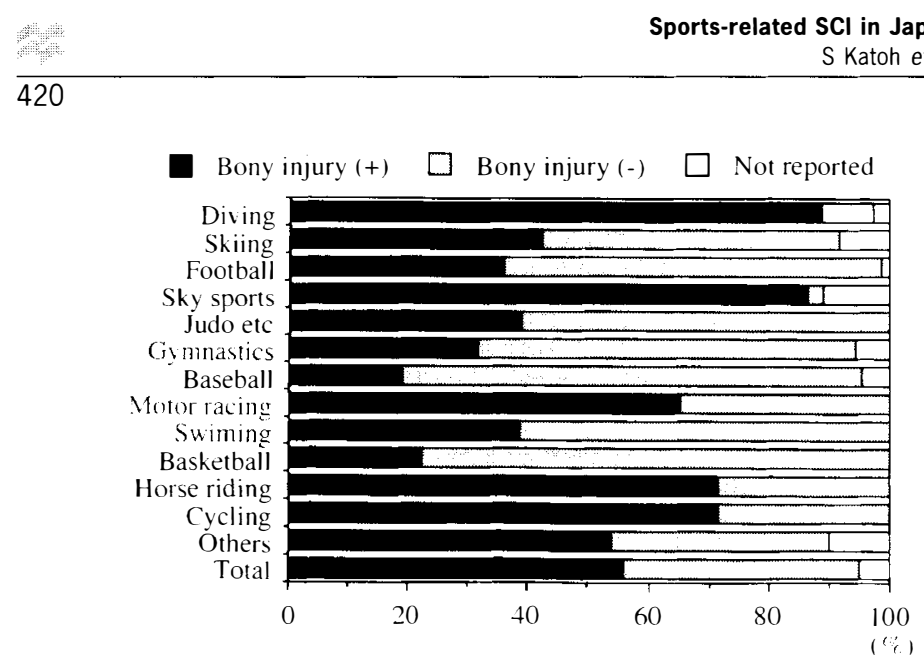

Figure 5 Ratio of the presence of bony injury of the spine in individual sports activities

Table 4 Sports activity and bony injury

\begin{tabular}{lccc}
\hline & $\begin{array}{c}\text { Bony injury } \\
(+)\end{array}$ & $\begin{array}{c}\text { Bony injury } \\
(-)\end{array}$ & Not reported \\
Diving & 101 & 10 & 3 \\
Skiing & 30 & 35 & 6 \\
Football $^{1}$ & 24 & 42 & 1 \\
Sky sports $^{2}$ & 32 & 1 & 4 \\
Judo etc $^{2}$ & 14 & 22 & 0 \\
Gymnastics $^{\text {Baseball }}$ & 11 & 22 & 2 \\
Motor racing $_{\text {Swimming }}$ & 4 & 16 & 1 \\
Basketball & 13 & 7 & 0 \\
Horse riding & 5 & 8 & 0 \\
Cycling & 2 & 7 & 0 \\
Others & 5 & 2 & 0 \\
Total & 5 & 2 & 0 \\
\hline
\end{tabular}

': including rugby, American football and soccer. ${ }^{2}$ : including Judo, Sumo and wrestling

Football is being played with increasing enthusiasm in our country. About 155000 players practice rugby football and about 25000 play American football. These sports have caused $12.7 \%$ of all sports-related SCI or $0.9 \%$ of all SCI. Although SCI in rugby football and American football have been frequently reported, nationwide numbers of patients were not available in any country. ${ }^{4,20}$ The mechanism of the injuries has been well-studied, and these were located exclusively to the cervical spine. Bony injuries were detected in less than half of the patients, which is consistent with previous reports.

To our knowledge, epidemiological data on SCI related sky sports had not been available, and in the present study patients from sky sports accounted for $7.0 \%$ of sports-related SCI. This incidence was similar to that in judo $(6.8 \%)$, and gymnastics $(6.6 \%)$. Sky sports predominantly caused thoracic and lumbar injuries with bony injury, suggesting a high energy was applied when the accidents occurred.
The patients in the present study included accidents which took place during recreational activities as well as in competitive sports. The majority of these patients were young males under the age of 30 , and one-third of them sustained motor complete paralysis which probably caused severe residual disabilities. Every effort should be undertaken to protect young people from such accidents in sports and recreational activities. To establish a prevention programme in each sport activity, analyses of the details of the situation when the accidents occurred are mandatory, although they were not available in the present survey. An important concept that emerged is that of a mismatch between the skills of the sportsman and the task attempted. Activities that can be carried out safely in practice when no stress or strain is involved, can become difficult when people compete and in competitive sports involving body contact, emotion and desire to win can override a skilled performance. ${ }^{21}$ Therefore, supervised sports activities including adequate refereeing in rugby or other contact sports is important, especially for junior players who are often unskilled and lack understanding of correct and safe techniques. ${ }^{22.23}$ In rugby, football and American football, rules have been changed and in gymnastics, usage of the trampoline has been restricted to decrease catastrophic accidents. Silver stated that it is important to determine if changes in the method of executing the sports, changes in attitude of the participants and administrators, or changes by the laws governing those sports will prevent spinal injury. ${ }^{23,24}$

Although the percentage of sports-related SCI was small in the present study as compared to previous reports, ${ }^{14,16,25,26}$ it is not difficult to imagine an increase in number in the future. We have launched an injury prevention programme and a similar study will be made to evaluate the effect of the programme as well as the changes in the incidence and the pattern of SCI.

\section{Acknowledgements}

Injury Prevention Committee of the Japan Medical Society of Paraplegia is grateful for the grants from the Dr Yutaka Nakamura Memorial Foundation for the Disabled and from the Labour Welfare Corporation. Members of the Injury Prevention Committee of the Japan Medical Society of Paraplegia (JMSoP) are Doctors Hiroshi Abe, Takashi Akatsu, Yasuhiro Hatsuyama, Takaaki Ikata, Eiji Iwatsubo, Hiyoshi Kaneda, Tomohiko Koyanagi, Kiyoshi Otani, Takashi Sakou, Hikosuke Shingu, Yoshiharu Takemitsu, and Kenzo Yada. The members of Injury Prevention Programme Subcommittee of JMSoP are Doctors Norihiko Ando, Masamitsu Ijichi, Yoshinobu Iwasaki, Shinsuke Katoh, Jiro Kawamura, Akira Kurihara, Akio Nakajima, Ryuichi Nihei, Hirotsugu Oda, Tadanori Oguma, Mitsuru Ohama, Takashi Oowada, Tetsuro Satoh, Keiichiro Shiba, Keiichi Shibasaki, Sekio Tominaga, and Katsunori Yoshinaga. 


\section{References}

1 Shingu $\mathrm{H}$ et al. A nationwide epidemiological survey of spinal cord injuries in Japan from January 1990 to December 1992. Paraplegia 1995; 33: $183-188$.

2 Frankel HL et al. The value of postural reduction in the initial management of closed injuries of the spine with paraplegia and tetraplegia. Paraplegia 1969; 7: 179-192.

3 Hashimoto $\mathrm{S}$ et al. Response bias in the nationwide epidemiological survey of an intractable disease in Japan. J Epidemiol 1991; 1: $27-30$.

4 Cantu RC, Mueller FO. Catastrophic spine injuries in football (1977-1989). J Spinal Disord 1990; 3: 227 -...231.

5 Clark KS. A survey of sports-related spinal cord injuries in schools and colleges, 1973-1975. J Safety Res 1977; 9: 140-147.

6 Damjan H, Turk PR. Prevention of spinal injuries from diving in Slovenia. Paraplegia 1995; 34: $246-249$.

7 Hamilton MG, Tranmer BI. Nervous system injuries in horseback-riding accidents. J Trauma 1993; 34: 227-232.

8 Maynard FM, Krasnick R. Analysis of recreational off-road vehicle accidents resulting in spinal cord injury. Ann Emerg Med 1988; 17: 30 - 33 .

9 Reynen PD, Clancy WG. Cervical spine injury, hockey helmets. and face mask. Am J Sports Med 1994; 22: 167-170.

10 Schneider RC et al. Serious and fatal football injuries involving the head and spinal cord. JAMA 1961; 177: 362-367.

11 Odor JM et al. Incidence of cervical spinal stenosis in professional and rookie football players. Am J Sports Med 1990; 18: $507-509$.

12 Scher AT. Catastrophic rugby injuries of the spinal cord: changing patterns of injury. Br J Sports Med 1991: 25: 57 - 60.

13 Torg JS et al. Neurapraxia of the cervial spinal cord with transient quadriplegia. J Bone Joint Surg [Am] 1986; 68-A: $1354-1370$.
14 Bailes JE et al. Diving injuries of the cervical spine. Surg Neurol 1990; 34: $155-158$

15 Branche CM et al. Water recreation-related spinal injuries: risk factors in natural bodies of water. Accid Anal Prev 1991; 23: 13 17.

16 Thurman DJ et al. Surveillance of spinal cord injuries in Utah, USA. Paraplegia 1994; 32: 665-669.

17 Green BA et al. Analysis of swimming pool accidents resulting in spinal cord injury. Paraplegia 1980; 18: $94-100$.

18 Good RP, Nickel VL. Cervical spine injuries resulting from water sports. Spine 1980; 5: $502-506$

19 Frymoyer JW, Pope MH, Kristiansen T. Skiing and spinal trauma. Clin Sports Med 1982; 1: 309.

20 Silver JR, Stewart D. The prevention of spinal injuries in rugby football. Paraplegia 1994; 32: $442-453$.

21 Tall RL, DeVault W. Spinal injury in sport: epidemiologic considerations. Clin Sports Med 1993; 12: $441-448$.

22 Milburn PD. Biomechanics of rugby union scrummaging. Technical and safety issues. Sports Med 1993; 16: 168 - 179.

23 Silver JR. Spinal injuries in sports in the UK. Br J Sports Med 1993; 27: $115-120$

24 Torg J. Epidemiological, pathomechanics, and prevention of athletic injuries to the cervical spine. In The Cervical Spine Research Society Editorial Committee (ed). The Cervical Spine. 2nd edn. J.B. Lippincot: Philadelphia 1989, pp. $442-463$.

25 Burke DC. Toscano J. Incidence and distribution of spinal cord injury. Menzies Technical Report 1987; 1:13-47.

26 Tator $\mathrm{CH}$ et al. Changes in epidemiology of acute spinal cord injury from 1947 to 1981. Surg Neurol 1993; 40: 207-215. 